\title{
How fleeting is fame? Collective memory for popular music
}

\author{
Stephen Spivack, Sara Philibotte, Nathaniel Hugo Spilka, Ian Passman \& Pascal Wallisch \\ Department of Psychology \\ New York University
}

\begin{abstract}
In this paper, we investigated the collective memory for popular music. To assess how well number-one hits are recognized over time, we randomly selected top songs from the last 76 years and presented them to a large sample of mostly millennial participants. In response to hearing each selection, participants were prompted to indicate whether they recognized each song. We found three distinct phases in collective memory: a steep linear drop-off in recognition for the music from this millennium, a stable plateau from the 1960s to the 1990s, and a further but more gradual drop-off for music from the 1940s and 1950s. More than half of recognition variability between songs can be accounted for by exposure as measured by Spotify play counts. We conclude that in the musical realm, fame is fleeting-but perhaps not as fleeting as previously suggested.
\end{abstract}

Keywords: Music, collective memory, culture, fame, popularity

Corresponding author: Pascal Wallisch, 6 Washington Place, Room 402, New York, NY, 10003. Email: pascal.wallisch@nyu.edu 


\section{Introduction}

Ever since the pioneering work of Ebbinghaus in 1885 (Ebbinghaus, 1885), the study of individual memory has been a mainstay of cognitive psychology - even during the darkest days of behaviorism (Bartlett, 1933) - flourishing to the present day (Schacter, 1999; Ormrod, 2017). In contrast, the study of collective memory - what groups of people or entire cultures know-has received comparatively little scientific attention (Wertsch \& Roediger, 2008; Roediger \& Abel, 2015). This state of affairs persists despite longstanding popular interest in this question, as exemplified by speculations about archetypes (Jung, 1969) and the collective consciousness (Durkheim, 1893). There are also other considerations: if one strives for fame, how durable or fleeting can one expect this fame to be? Surely, one could expect it to last for more than 15 minutes, as has been previously suggested (Perry, 2005).

There is an even bigger issue: if cultures are to learn from history, they have to be aware of it in the first place (Assmann \& Czaplicka, 1995). However, it is largely unknown how much history people remember. Cognitive psychologists have begun to investigate this question in studies that probe collective memory of political leaders both in the United States (Roediger \& DeSoto, 2014) and in China (Fu et al., 2016). Results support the existence of a serial position effect (Murdock, 1962) in collective memory, in which the recency portion shows a linear decline.

We are not aware of existing literature that has investigated collective memory for cultural media such as music, art and film. Importantly, exposure to artifacts in these domains is typically driven by personal interest-in other words, it is self-selective. Conversely, exposure to historical leaders is usually involuntary and often within academic settings, which could affect remembering over time. Thus, we wondered whether such effects are also found in other kinds of collective memory, in particular that for popular music. It is conceivable that we will find a serial position effect similar to that observed for political leaders, but it is also possible that there is a "cultural horizon" beyond which even once popular music is effectively forgotten. Should this cultural horizon exist, we aimed to characterize the drop-off as either linear (Rubin, 2014) or exponential (Ebbinghaus, 1913). Finally, there might be some "evergreen" songs that are remembered regardless of how long ago they were first popular, akin to flashbulb memories (Brown \& Kulik, 1977). We attempted to empirically address these questions in this paper. 


\section{Method}

In this paper, we aimed to measure the recognition of popular music.

\section{Materials}

We operationalized "popular music" as music that reached the top of the Billboard Top 100 between the years 1940 and 1957 and of the Billboard Hot 100 from 1958 to 2015 (we refer to both together as the Billboard henceforth). The Billboard is a record chart for the top singles in the United States and is the industry standard by which the popularity of contemporary music is measured. Rankings are published each week and are currently based on three components: online streaming, radio airtime, and record sales-both physical and digital (Billboard, 2018). We randomly selected two of the top songs from each year-for a total of 152 songs (see Appendix for a list of the songs we used)-and presented them to participants via Audio-Technica ATH-M20x Professional Monitor Headphones using custom-built MATLAB (2016b) software (Mathworks, Natick, MA). As a proxy for self-selected exposure to music, we recorded the play count for each song as it appeared on Spotify - the world's largest collection of digital music, with over 140 million subscribers (Spotify, 2018)—on October $8^{\text {th }}, 2017$.

\section{Participants and task}

To satisfy statistical power needs (Wallisch, 2015), we used a sufficiently large sample to address our research questions. Every participant $(n=643)$ was presented with a random selection of seven out of the 152 songs and asked to report whether they recognized each. To confirm the validity of our recognition assay, participants were also presented with 5-, 10- and 15-second excerpts from each song. These clips were selected from the 152 songs and randomly presented throughout the experiment. Participants were recruited from the New York University student population as well as the greater New York metropolitan area. Our sample consisted mostly of young participants, with a mean age of 21.3 years, a median age of 20 years and a standard deviation of 5.09 years. The majority (88\%) of this sample was between the ages of 18 and 25, which we considered to be "millennials". All procedures were approved by the New York University Institutional Review Board, the University Committee on Activities Involving Human Subjects (UCAIHS).

\section{Data analysis}

630 participants ( $98 \%$ of the total) completed the entire study and were used in this analysis. As much of our data is nonlinear, we used Spearman's rho to quantify the strength of the relationship between any two variables, such as recognition and play count. Pairwise $\mathrm{t}$-tests were used to determine statistically significant differences between the parameters-such as recognition proportion-for each phase. To guard against false positives and to compensate for multiple comparisons, we adopt a significance level of 0.005 (Benjamin et al., 2017). This is adequate, as our study is sufficiently powered. We would like to emphasize that we used participants of all ages in the analysis that is presented here. When restricting the same analysis to millennials (aged 18-25, $n=564$ ), we found that there is no meaningful difference in our results when compared to our entire participant pool-only minor numerical differences. This is probably due to the fact that our full sample overwhelmingly consisted of participants in that age range. 


\section{Results}

The main question of this paper is whether there is a cultural horizon for the collective memory for popular music and if so, where this horizon is and how it is approached. To answer this, we calculated the proportion of participants who reported to recognize each song and plotted this proportion as a function of the year it reached the number-one spot on the Billboard. The results of this analysis are presented in Figure 1.

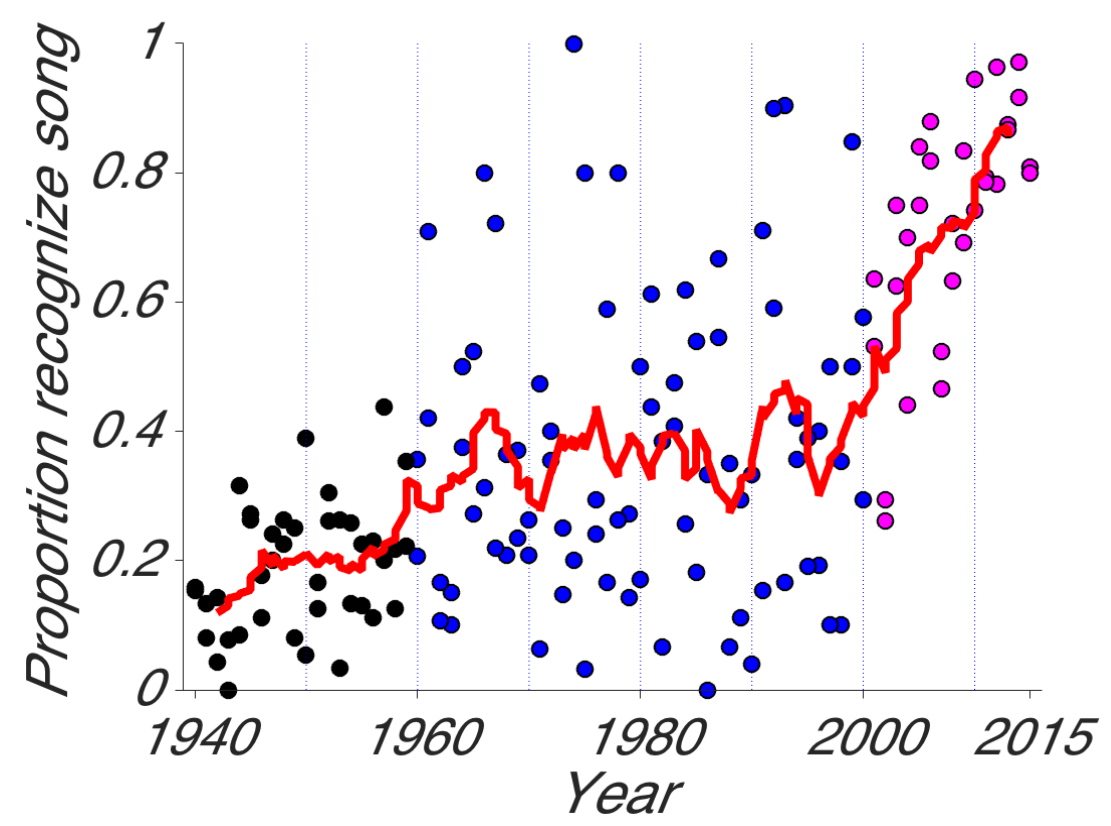

Figure 1: Recognition of songs over time. Dots represent the proportion of participants who reported to recognize a given song from a given year. The red curve represents the convolved average proportion for a given year, integrating over 5 years. Magenta dots represent songs from phase 1 (2001 to 2015), blue dots represent songs from phase 2 (1960 to 2000) and black dots represent songs from phase 3 (1940 to 1959). Dashed vertical lines are decade markers.

The proportion of participants who reported to recognize a given song increases with how recently it occupied the number-one spot on the Billboard ( $r=0.62, \mathrm{p}=1.70 \mathrm{e}-17)$. This is not surprising and could be considered a manipulation check. As can be seen in Figure 1, this trend is far from linear. Whereas the average recognition proportion across all songs and all years is 0.39 , we observed three distinct phases in collective memory. Phase 1 : recognition was high, but decreases steeply and linearly from 2015 until the turn of the millennium. Phase 2: there was a stable plateau at an average recognition proportion of 0.37 from the late 1990 s to the early 1960s. Phase 3: starting in the late 1950s, recognition was quite low and slowly decreased toward oblivion.

We asked our participants to indicate whether they recognized each song, which probed the feeling of recognition at the time they heard it - not whether they could accurately select the title from a list of related titles. This raises the question of whether our assay is a valid means of capturing recognition memory. To confirm the validity of this method, we replicated the above finding (see Figure 1) using short excerpts (5-, 10- or 15-second clips) 
that we deemed to be representative of each song. The results of this analysis are presented in Figure 2.

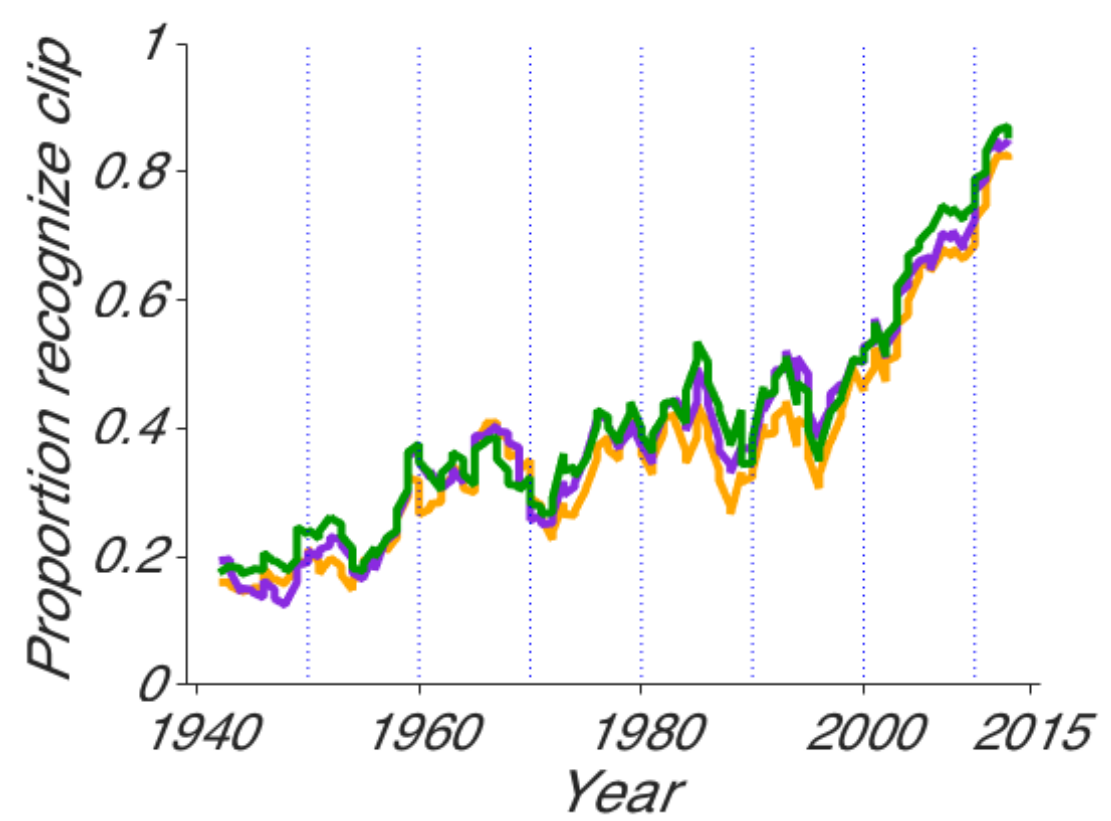

Figure 2: Recognition of clips over time. Orange curve: 5 second clips, purple curve: 10 second clips, green curve: 15 second clips. All three curves represent the convolved average proportion for a given year, integrating over 5 years. Dashed vertical lines are decade markers.

Recognition for clips is remarkably similar to that of songs $(r=0.97, p=1.12 \mathrm{e}-89)$, regardless of clip duration. Indeed, none of the clip durations yields recognition rates that are statistically distinguishable from that of the songs $(\mathrm{p}=0.19, \mathrm{p}=0.14, \mathrm{p}=0.02$, for clip durations of 5-, 10- and 15-seconds, respectively). In absolute terms, the mean recognition for 5 -second clips is 0.38 , for 10 -second clips is 0.40 and for 15 -second clips is 0.42 . The difference between the recognition proportions for 5-second clips and 10-second clips is statistically significant $(\mathrm{t}=3.18, \mathrm{p}=0.0018, \mathrm{df}=151)$, the difference between 5 -second and 15 -second clips is also statistically significant $(t=4.42, p=1.88 \mathrm{e}-05, \mathrm{df}=151)$, but the difference between 10-second and 15-second clips is not $(t=1.26, p=0.21, d f=151)$. This is visually evident in the figure above, as the orange trace tends to be below the purple trace, which in turns tends to be below the green trace-but the effect sizes are small: $d=$ $0.14, d=0.10$ and $d=0.04$ for the pairs listed above. Therefore, it seems that it only took 5 seconds for participants to accurately report whether they recognized a given song from a clip. This is consistent with the finding that, in response to hearing an excerpt of a song, people can reliably categorize its genre in as little as 250 milliseconds (Gjerdingen \& Perrott, 2008). As there is no difference in recognition between clips and songs, we conclude that we used a valid metric of recognition memory-participants respond far from randomly. 
Next, we quantified the mean song recognition proportion and mean variability-defined here as the average residual from the convolved mean-for each of the three phases we identified in Figure 1. For the results of this analysis, see Figure 3.
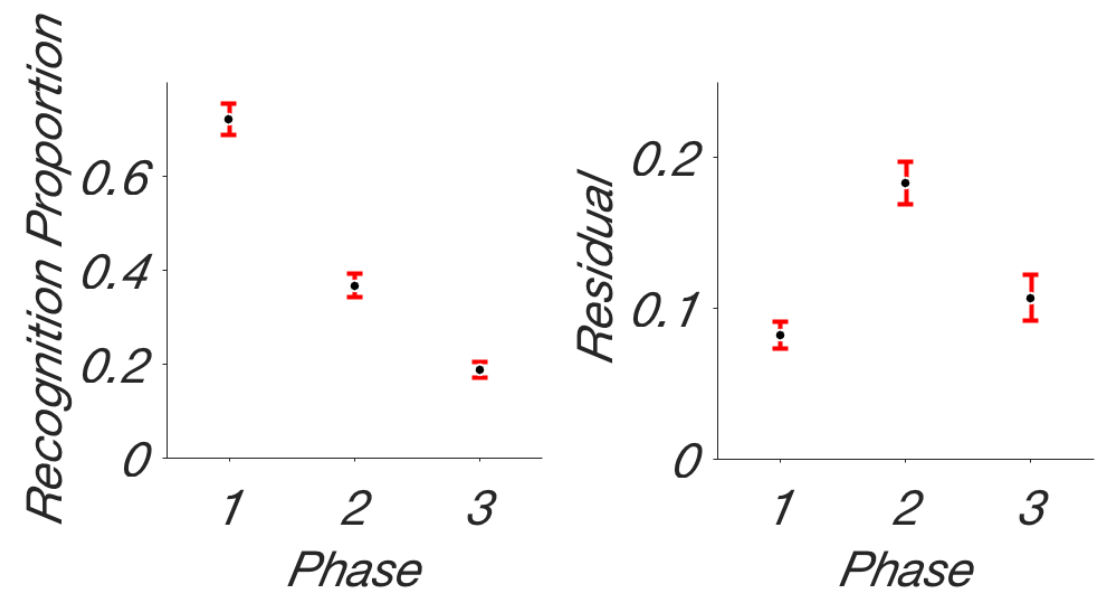

Figure 3: Quantifying average song recognition proportions and their variability over the three phases. Left panel: Black dots represent the mean recognition rate for a given phase. Red bars represent the standard error of the mean. Right panel: Black dots represent the average residual-the distance between individual songs to the corresponding point on the convolved average (red curve) from figure 1, for a given phase. Red bars represent the standard error of the mean.

The mean recognition proportions for each of the three phases are $0.72,0.37$ and 0.19 , respectively. To confirm that the difference between each phase is statistically significant, we performed a pairwise t-test to compare Phases 1 and 2, Phases 2 and 3, and Phases 1 and 3 ( $\mathrm{p}=7.41 \mathrm{e}-06, \mathrm{p}=1.43 \mathrm{e}-11$ and $\mathrm{p}=4.11 \mathrm{e}-24$, respectively).

For the mean residual of each phase, we observed a different pattern: during Phase 1-and to a lesser extent Phase 3-the recognition proportion of individual songs closely follows the mean for a given year. In contrast, inter-song variability is high during Phase 2, where the mean does not closely represent recognition rates of individual songs. Some songs in this phase are recognized extremely well, such as "When A Man Loves A Woman" by Percy Sledge (1966) whereas others like "Knock Three Times" by Dawn (1971) are all but forgotten. The mean residual for each phase is $0.08,0.18$ and 0.11 , respectively. When we performed a pairwise t-test to determine whether this observation is supported by the data, we found that Phases 1 and 2 and Phases 2 and 3 both have a statistically significant difference from each other ( $p=0.005$ and $p=1.68 \mathrm{e}-05$, respectively), but that Phases 1 and 3 do not $(p=0.14)$. Thus, recognition variability is high during Phase 2 . This raises the question of what drives the variability in recognition, both between phases and between songs within a given phase. One possible explanation for the former is simply exposure: people are more likely to recognize songs that they have been exposed to more often (Peretz, Gaudreau \& Bonnel, 1998).

To address the question of whether exposure can account for a sufficiently large proportion of recognition variability, we used play counts on a digital streaming servicein this case, Spotify-as a proxy for self-selected exposure to music and plotted them against recognition proportion. The results of this analysis are presented in Figure 4. 


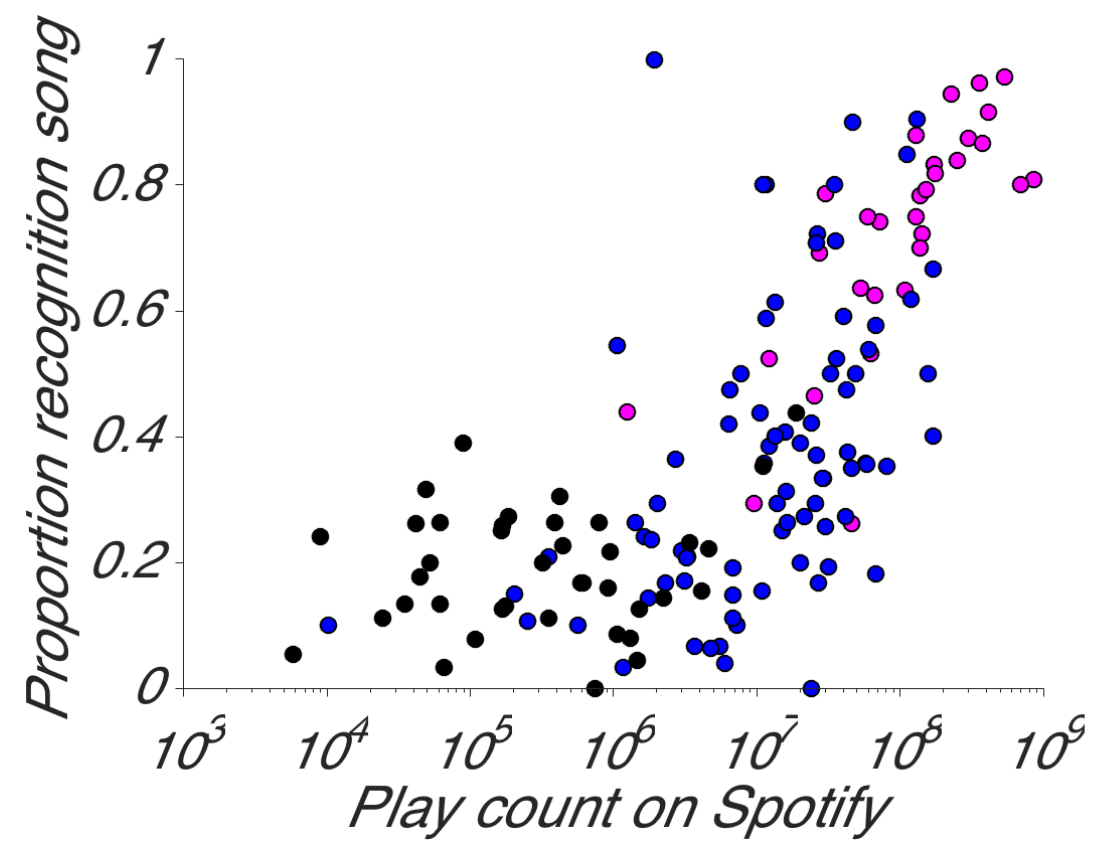

Figure 4: Recognition vs. play count. Magenta dots represent songs from phase 1 (2001 to 2015), blue dots represent songs from phase 2 (1960 to 2000) and black dots represent songs from phase 3 (1940 to 1959). Note the log scale on the $\mathrm{x}$-axis.

There is a considerable correlation between the play count on Spotify and the likelihood of recognizing a given song. This relationship is statistically reliable when assessed with Spearman's rho (Spearman, 1904): $r=0.73, \mathrm{p}=6.09 \mathrm{e}-27$. A substantial amount-just over half-of the variability in recognition proportion can be accounted for by Spotify play counts. This is remarkable given that Spotify was launched in 2008, well after the majority of this music was released, suggesting that the relatively young cohort of participants in our study consumes music primarily through digital streaming.

Given the results of research on collective memory in other domains, we would not have expected the stable plateau - characterized by high within-phase recognition variabilitywhich we found. One possibility is that this phase results from our participants listening to the music of their parents, when growing up in their household, as suggested by studies on the autobiographical memory of music (Rathbone, Moulin \& Conway, 2008; Barrett et al., 2010; Krumhansl \& Kupnik, 2013). Another possibility is that the music from the 1960s onwards truly was different from earlier music, with music from the 1960s to the 1990s representing a particularly special time in music. We know from the history of music that music really did change dramatically from the 1960s onward-the common practice period transitioned into rock music and then electronically-generated music (Ted Coons, personal communication, 01/23/2018). Moreover, the lyrics of popular music also change. Starting in the 1960s, we see political music, whereas prior to that time, love songs dominate, as shown by a content analysis (Henard \& Rossetti, 2014). These possibilities are not mutually exclusive, but we wondered if we could find further support for the notion that the 1960 s to 1990 s were a unique time in terms of popular music. To address this issue, we looked at the diversity of song titles over time. To quantify this trend, we plotted the 
number of unique titles that occupied the number-one spot as a function of year. In years during which this number was low, few titles managed to hog the top spot; in years in which there was fierce competition between equally popular but different songs, this number was high, as it was more difficult for any given song to stay on top for long. For the results of this analysis, see Figure 5.

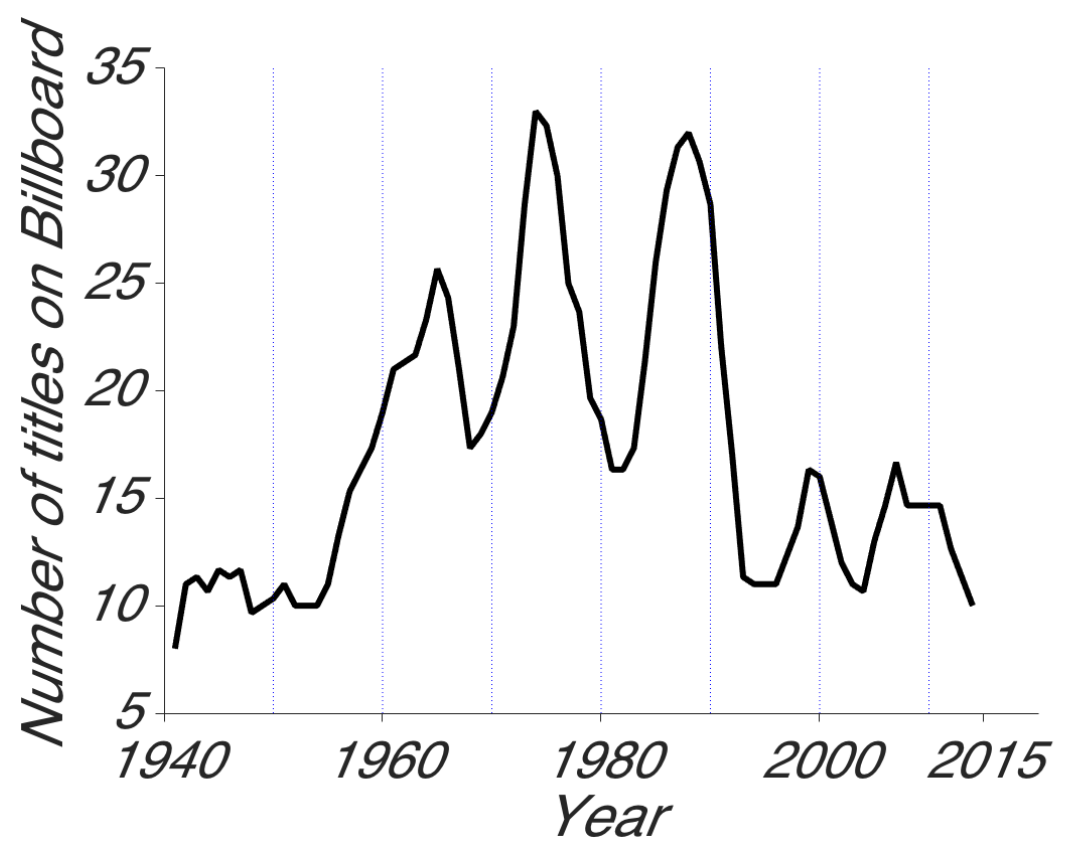

Figure 5: Musical diversity over time. Note that the data was smoothed by a 3-year moving average. A value of just above 10 in the early 1940s means that an average song was on top of the charts for over 4 weeks in a row. The peak levels in the mid-1970s mean that the average song was only on top of the charts for little more than a week during that period.

We observed three distinct phases similar to those seen in Figure 1. Phase 1: low diversity from 2015 to the 1990s. Phase 2: high diversity from the 1960s to the 1990s. Phase 3: low diversity-again - from the 1940s to the end of the 1950s. Diversity here means the number of unique singles that occupied the number one spot during a given year. To quantify the diversity in titles over time, we first binned the data according to the phases we identified in Figure 1 and then computed the mean and standard error of the mean for each. The mean for each of the three phases is $6.73,11.32$ and 6.14 , respectively. Next, we used a pairwise t-test to confirm that there is again a statistically significant difference between Phases 1 and 2 and Phases 2 and 3, but not Phases 1 and 3 ( p = 3.30e-05, p = $6.41 \mathrm{e}-08$ and $\mathrm{p}=0.14$, respectively). This pattern is undeniable, but we cannot divine the reasons behind it. Anything we could propose, such as changes in listening habits and technology or the rise of club culture and dance music, would be purely speculative. However, there seem to be distinct diversity peaks in almost every decade, which could lead to the suggestion of "boom and bust" cycles in music, giving each decade a unique sound when the old sound has "played out". 


\section{Discussion}

We identified three distinct phases in the collective memory for popular music. The first phase is characterized by generally high recognition, with a steep linear drop-off from 2015 to the late 1990s; in this phase, inter-song variability is low. A stable plateau of moderately high recognition, with high inter-song variability, characterizes the second phase; some songs are well remembered, whereas others are not. In the third and final phase, recognition drops again - to rather low levels-as time passes, and inter-song variability is relatively low again. We also found that a sizable proportion-more than half-of this recognition variability can be accounted for by self-selected exposure to music.

We interpret these findings to mean that collective memory for popular music-and perhaps for cultural artifacts in general-is different than that for political leaders, be they in the United States (Roediger \& DeSoto, 2014) or China (Fu et al., 2016). There are two important differences. First, the drop-off we observed is only linear for a short period, until it hits the recognition plateau from the 1960s to the 1990s. Second, there seems to be no primacy effect for popular music. There are several possible explanations for this. For instance, the primacy effect for political leaders presumably stems from the fact that the founders of a political dynasty are frequently repeated in public discourse. Conversely, people demonstrably do not elect to listen to songs from the early years of the Billboard, if Spotify play counts are a valid metric of exposure. In fact, play counts for this period are remarkably low (see Figure 4). The issue of play counts highlights another difference between existing work on collective memory for political leaders and our work here. Presumably, people are exposed to political leaders in history classes and coursework, much of which is part of mandatory schooling. In contrast, much-if not most-of music listening is both voluntary and self-selective. There are other differences as well. The number of historical leaders is countably finite-in terms of United States presidents, there have been only 45 to date. However, the universe of existing music is vast and-from the perspective of an individual-basically boundless. Given this consideration, it is surprising that our recognition rates are as high as they are. As there are strong recency effects for both Chinese and American leaders-but not for popular music - the actionable advice would be that if one wants to remain famous in politics, they need to found a dynasty. Conversely, if one wants to remain famous for their art, they have to keep producing new releases, or release them during a special period that increases the chances of being remembered. Few things will stand the test of time, in particular if they are not repeated. Finally, our work involved reports of recognition in response to a specific stimulus whereas most existing work on collective memory used free recall. One paper that did use recognition methods-again on United States political leaders-suggests a proneness to false-positives due to contextual familiarity (Roediger \& DeSoto, 2016), as has been shown previously for other material (Roediger \& McDermott, 1995).

In addition, these results put the notion of a hard "cultural horizon" in question. We do not find a period during which recognition drops to zero. Even our millennial participantswhich formed the bulk of our participant pool-were not completely unaware of the music that was popular in the 1940s. We posit several plausible explanations for this. For 
instance, it is possible that not enough time has passed since the first titles of our stimuli set. Perhaps a future study might be able to identify when recognition hits zero (the cultural horizon), if there is a long enough history of Billboard music. However, it is also possible that involuntary exposure through film, TV and radio or accidental exposure through music discovery services such as Pandora allows people to discover music that might be very old indeed. Finally, people might also intentionally seek out the music of previous generations. In principle-as much, if not all music is recorded and digitally available forever - this could prevent a cultural horizon indefinitely. We are unable to distinguish these possibilities in the present study.

This study has other limitations as well. For instance, we used Spotify play counts as a proxy for total music exposure. We do not have data on how often individuals listen to music in analog format, on other web-based platforms or on the radio, or are exposed to music in everyday life. Put differently, all of the observed recognition effects might be entirely driven by exposure, but our measure of exposure is noisy if not biased, lowering the proportion of variance in recognition rates. In addition, it is possible that newer music has greater play counts on Spotify for several reasons, none of which are mutually exclusive, and none of which we can distinguish. For instance, older music might be more readily available in analog formats such as cassette tapes or LP records, which could lower the digital play count of such music. Conversely, it is also possible that the average Spotify user-who is between the age of 13 and 29 (Spotify, 2018)-preferentially listens to the music of their generation. In this cohort, that corresponds to music from the 2000s and 2010s. However, this line of reasoning is not central to our argument that distinct phases exist. That we can account for as much of the variance in recognition as we do, simply with Spotify play counts, does suggest that this is a reasonable proxy for exposure in general, and that voluntary exposure through digital streaming is a main driver of recognition. This does not preclude that there are other factors that influence recognition as well. A related limitation is that most of our participants were young adults. Presumably, if we had multiple age cohorts, the linear recency peaks would average out, perhaps yielding an overall flat recognition curve. In that sense, it was good that our sample overrepresented a single generation. We predict that future studies with multiple age cohorts will exemplify distinct and shifted recency peaks that are unique to a given age cohort. A final limitation worth noting is that we did not test recognition strictly speaking-but rather the feeling of recognition-as we asked participants whether they recognized what they heard, not whether they could select the title of the song from a list of related titles. Whether this report is actually accurate remains unknown. However, we would like to emphasize that our findings have face validity. It would be surprising if our cohort of millennials reported higher recognition rates for music before their time. Yet, that is not what we find. Moreover, the strong correlation with exposure and the concordance between clip and song recognition patterns would be very surprising if participants responded randomly. Thus, we conclude that this measure of recognition is reasonably valid. To get an estimate of the false recognition rate, it would be advisable to include a piece of unpublished music in the stimulus set as a lure.

Taken together, the most compelling interpretation supported by our data is the notion that the period from the 1960 s to the 1990 s really was special, in terms of music. During 
this period, we observe an extended plateau characterized by relatively high recognition that is surprising given prior research on collective memory. However, to determine whether the music of the 1960s to 1990s was truly special will require a follow-up study in another 30 years or so. Our prediction is that in another generation, people will still preferentially listen to current music, but the linear drop off phase will be extended as the 1960s to 1990s plateau shifts back in time. The recognition curve might even have multiple peaks by then, as the plateau we identified in the current study will look much like a primacy effect, if the music of the 1960s to the 1990s appeals to the children of millennials. Conversely, if the autobiographical memory explanation is true (Krumhansl \& Zupnick, 2013), the general pattern should look much like it does now, only with an extended Phase 3 , that perhaps could even reach close to zero recognition. 


\section{References}

Assmann, J., \& Czaplicka, J. (1995). Collective Memory and Cultural Identity. New German Critique, (65), 125-133.

Bartlett, F. C., \& Burt, C. (1933). Remembering: A study in experimental and social psychology. British Journal of Educational Psychology, 3(2), 187-192.

Barrett, F. S., Grimm, K. J., Robins, R. W., Wildschut, T., Sedikides, C., \& Janata, P. (2010). Musicevoked nostalgia: affect, memory, and personality. Emotion, 10(3), 390.

Benjamin, D. J., Berger, J. O., Johannesson, M., Nosek, B. A., Wagenmakers, E. J., Berk, R., ... \& Cesarini, D. (2017). Redefine statistical significance. Nature Human Behaviour, 1.

Brown, R., \& Kulik, J. (1977). Flashbulb memories. Cognition, 5(1), 73-99.

Durkheim, Emile. The Division of Labour in Society. Trans. W. D. Halls, intro. Lewis A. Coser. New York: Free Press, 1997

Ebbinghaus, H. (1913). Memory: A contribution to experimental psychology (No. 3). University Microfilms.

Fu, M., Xue, Y., DeSoto, K. A., \& Yuan, T. F. (2016). Remembering the leaders of China. Frontiers in psychology, 7.

Gjerdingen, R. O., \& Perrott, D. (2008). Scanning the dial: The rapid recognition of music genres. Journal of New Music Research, 37(2), 93-100.

Guinn, J., \& Perry, D. (2005). The sixteenth minute: life in the aftermath of fame. Tarcher.

Henard, D. H., \& Rossetti, C. L. (2014). All You Need is Love?: Communication Insights From Pop Music's Number-One Hits. Journal of Advertising Research, 54(2), 178-191.

Jung, C.G. (1969). Archetypes and the Collective Unconscious [sic], Collected Works of C.G. Jung, Volume 9 (Part 1), Princeton, N.J.: Princeton University Press.

Krumhansl, C. L., \& Zupnick, J. A. (2013). Cascading reminiscence bumps in popular music. Psychological science, 24(10), 2057-2068.

Murdock Jr, B. B. (1962). The serial position effect of free recall. Journal of experimental psychology, $64(5), 482$.

Number of global monthly active Spotify users from July 2012 to June 2017. (2018). Retrieved from https://www.statista.com/statistics/367739/spotify-global-mau/

Ormrod, J. E. (2017). How We Think and Learn: Theoretical Perspectives and Practical Implications. Cambridge University Press.

Peretz, I., Gaudreau, D., \& Bonnel, A. M. (1998). Exposure effects on music preference and recognition. Memory \& Cognition, 26(5), 884-902.

Rathbone, C. J., Moulin, C. J., \& Conway, M. A. (2008). Self-centered memories: The reminiscence bump and the self. Memory \& Cognition, 36(8), 1403-1414.

Roediger, H. L., \& McDermott, K. B. (1995). Creating false memories: Remembering words not presented in lists. Journal of experimental psychology: Learning, Memory, and Cognition, 21(4), 803.

Roediger, H. L., \& DeSoto, K. A. (2014). Forgetting the presidents. Science, 346(6213), 1106-1109.

Roediger, H. L., \& Abel, M. (2015). Collective memory: a new arena of cognitive study. Trends in cognitive sciences, 19(7), 359-361.

Roediger, H. L., \& DeSoto, K. A. (2016). Recognizing the presidents: was Alexander Hamilton president?. Psychological Science, 27(5), 644-650.

Rubin, D. C. (2014). How quickly we forget. Science, 346(6213), 1058-1059.

Schacter, D. L. (1999). The seven sins of memory. Insights from psychology and cognitive neuroscience. American Psychologist, 54, 182-203.

Spearman, C. (1904). The proof and measurement of association between two things. The American journal of psychology, 15(1), 72-101. 
The week's most popular songs across all genres. (2018). Retrieved from https://www.billboard.com/biz/charts/the-billboard-hot-100

Wallisch, P. (2015). Brighter than the sun: Powerscape visualizations illustrate power needs in neuroscience and psychology. arXiv preprint arXiv:1512.09368.

Wertsch, J. V., and Roediger III, H. L. (2008). Collective memory: conceptual foundations and theoretical approaches. Memory 16, 318-326.

\section{Acknowledgments}

We would like to thank Lucy Cranmer, Warren Ersly, Caroline Myers, Mir Hwang and Ted Coons for helpful comments on a prior version of this manuscript. We would also like to thank the Deans Undergraduate Research Fund (DURF) at New York University for financial support of this project. 


\section{Appendix}

\begin{tabular}{|c|c|c|c|c|}
\hline Year & Song & Artist & Recognition & Playcount (M) \\
\hline 2015 & What Do You Mean? & Justin Bieber & 0.81 & 859.455 \\
\hline 2015 & See You Again & Wiz Khalifa ft. Charlie Puth & 0.80 & 693.251 \\
\hline 2014 & All About That Bass & Meghan Trainor & 0.92 & 411.734 \\
\hline 2014 & Happy & Pharrell Williams & 0.97 & 533.017 \\
\hline 2013 & Wrecking Ball & Miley Cyrus & 0.88 & 300.566 \\
\hline 2013 & Locked Out of Heaven & Bruno Mars & 0.87 & 377.360 \\
\hline 2012 & Diamonds & Rihanna & 0.96 & 355.862 \\
\hline 2012 & Stronger (What Doesn't Kill You) & Kelly Clarkson & 0.78 & 136.752 \\
\hline 2011 & Black and Yellow & Wiz Khalifa & 0.79 & 151.211 \\
\hline 2011 & Hold It Against Me & Britney Spears & 0.79 & 30.247 \\
\hline 2010 & Not Afraid & Eminem & 0.94 & 228.394 \\
\hline 2010 & $\mathrm{OMG}$ & Usher ft. Will.I.Am. & 0.74 & 71.893 \\
\hline 2009 & Fireflies & Owl City & 0.83 & 172.616 \\
\hline 2009 & "3" & Britney Spears & 0.69 & 27.400 \\
\hline 2008 & Whatever You Like & T.I. & 0.63 & 107.525 \\
\hline 2008 & Bleeding Love & Leona Lewis & 0.72 & 142.313 \\
\hline 2007 & Give It To Me & Timbaland & 0.47 & 25.404 \\
\hline 2007 & This Is Why I'm Hot & Mims & 0.52 & 12.224 \\
\hline 2006 & Irreplaceable & Beyonce & 0.88 & 129.371 \\
\hline 2006 & SexyBack & Justin Timberlake & 0.82 & 174.620 \\
\hline 2005 & Gold Digger & Kanye West ft. Jamie Foxx & 0.84 & 250.227 \\
\hline 2005 & Hollaback Girl & Gwen Stefani & 0.75 & 129.048 \\
\hline 2004 & Drop It Like It's Hot & Snoop Dogg ft. Pharrell & 0.70 & 137.306 \\
\hline 2004 & I Believe & Fantasia & 0.44 & 1.239 \\
\hline 2003 & Baby Boy & Beyonce ft. Sean Paul & 0.75 & 59.249 \\
\hline 2003 & Get Busy & Sean Paul & 0.63 & 66.823 \\
\hline 2002 & Foolish & Ashanti & 0.26 & 45.958 \\
\hline 2002 & Ain't It Funny & Ja Rule \& Jennifer Lopez & 0.29 & 9.535 \\
\hline 2001 & Family Affair & Mary J. Blige & 0.53 & 62.546 \\
\hline 2001 & Bootylicious & Destiny's Child & 0.64 & 53.028 \\
\hline 2000 & Come On Over Baby (All I Want Is You) & Christina Aguilera & 0.29 & 13.801 \\
\hline 2000 & Smooth & Santana ft. Rob Thomas & 0.58 & 68.081 \\
\hline 1999 & Bills, Bills, Bills & Destiny's Child & 0.50 & 32.467 \\
\hline 1999 & ...Baby One More Time & Britney Spears & 0.85 & 110.882 \\
\hline 1998 & Lately & Divine & 0.10 & 0.563 \\
\hline 1998 & Truly Madly Deeply & Savage Garden & 0.35 & 80.557 \\
\hline 1997 & 4 Seasons of Loneliness & Boyz II Men & 0.10 & 7.211 \\
\hline 1997 & Hypnotize & Notorious B.I.G. & 0.50 & 157.181 \\
\hline 1996 & No Diggity & Blackstreet ft. Dr. Dre & 0.40 & 169.896 \\
\hline 1996 & One Sweet Day & Mariah Carey \& Boyz II Men & 0.19 & 31.435 \\
\hline 1995 & Exhale (Shoop Shoop) & Whitney Houston & 0.19 & 6.748 \\
\hline 1995 & Have You Ever Really Loved A Woman? & Bryan Adams & 0.39 & 20.164 \\
\hline 1994 & I Swear & All-4-One & 0.42 & 23.837 \\
\hline 1994 & Bump N' Grind & R. Kelly & 0.36 & 57.611 \\
\hline 1993 & Informer & Snow & 0.17 & 26.780 \\
\hline 1993 & I Will Always Love You & Whitney Houston & 0.90 & 130.382 \\
\hline 1992 & Baby Got Back & Sir Mix-A-Lot & 0.90 & 46.558 \\
\hline 1992 & Jump & Kriss Kross & 0.59 & 40.487 \\
\hline 1991 & Joyride & Roxette & 0.15 & 10.877 \\
\hline 1991 & Gonna Make You Sweat (Everybody Dance Now) & C\&C Music Factory & 0.71 & 35.426 \\
\hline 1990 & Praying For Time & George Michael & 0.04 & 5.976 \\
\hline 1990 & How Am I Supposed To Live Without You? & Michael Bolton & 0.33 & 29.067 \\
\hline 1989 & If You Don't Know Me By Now & Simply Red & 0.29 & 25.694 \\
\hline 1989 & Lost In Your Eyes & Debbie Gibson & 0.11 & 6.797 \\
\hline 1988 & Every Rose Has Its Thorn & Poison & 0.35 & 45.721 \\
\hline
\end{tabular}




\begin{tabular}{|c|c|}
\hline 1988 & Roll With It \\
\hline 1987 & With Or Without You \\
\hline 1987 & Lean On Me \\
\hline 1986 & The Way It Is \\
\hline 1986 & Holding Back The Years \\
\hline 1985 & Money For Nothing \\
\hline 1985 & Heaven \\
\hline 1984 & Caribbean Queen \\
\hline 1984 & Footloose \\
\hline 1983 & Maniac \\
\hline 1983 & Flashdance... What A Feeling \\
\hline 1982 & Truly \\
\hline 1982 & Abracadabra \\
\hline 1981 & Kiss On My List \\
\hline 1981 & The Tide Is High \\
\hline 1980 & Magic \\
\hline 1980 & Rock With You \\
\hline 1979 & Sad Eyes \\
\hline 1979 & My Sharona \\
\hline 1978 & Shadow Dancing \\
\hline 1978 & Baby Come Back \\
\hline 1977 & You Light Up My Life \\
\hline 1977 & Gonna Fly Now \\
\hline 1976 & Love Machine \\
\hline 1976 & Saturday Night \\
\hline 1975 & I'm Sorry \\
\hline 1975 & Lady Marmalade \\
\hline 1974 & Can't Get Enough Of Your Love, Babe \\
\hline 1974 & The Loco-Motion \\
\hline 1973 & The Most Beautiful Girl \\
\hline 1973 & Top Of The World \\
\hline 1972 & Ben \\
\hline 1972 & Heart Of Gold \\
\hline 1971 & Gypsies, Tramps, \& Thieves \\
\hline 1971 & Knock Three Times \\
\hline 1970 & The Long and Winding Road \\
\hline 1970 & Everything is Beautiful \\
\hline 1969 & Wedding Bell Blues \\
\hline 1969 & Get Back \\
\hline 1968 & Love Child \\
\hline 1968 & Harper Valley P.T.A. \\
\hline 1967 & Hello Goodbye \\
\hline 1967 & The Happening \\
\hline 1966 & When A Man Loves A Woman \\
\hline 1966 & Monday, Monday \\
\hline 1965 & Help! \\
\hline 1965 & Eight Days A Week \\
\hline 1964 & Leader Of The Pack \\
\hline 1964 & Love Me Do \\
\hline 1963 & Easier Said Than Done \\
\hline 1963 & Go Away Little Girl \\
\hline 1962 & Soldier Boy \\
\hline 1962 & Don't Break The Heart That Loves You \\
\hline 1961 & The Lion Sleeps Tonight \\
\hline 1961 & Blue Moon \\
\hline 1960 & Are You Lonesome Tonight? \\
\hline 1960 & I'm Sorry \\
\hline 1959 & Sleepwalk \\
\hline 1959 & The Chipmunk Song \\
\hline
\end{tabular}

\begin{tabular}{|c|c|c|}
\hline Steve Winwood & 0.07 & 3.677 \\
\hline $\mathrm{U} 2$ & 0.67 & 169.532 \\
\hline Club Nouveau & 0.55 & 1.059 \\
\hline Bruce Hornsby and the Range & 0.00 & 24.203 \\
\hline Simply Red & 0.33 & 28.593 \\
\hline Dire Straits & 0.18 & 67.141 \\
\hline Bryan Adams & 0.54 & 60.783 \\
\hline Billy Ocean & 0.26 & 30.095 \\
\hline Kenny Loggins & 0.62 & 120.084 \\
\hline Michael Sembello & 0.48 & 42.039 \\
\hline Irene Cara & 0.41 & 15.736 \\
\hline Lionel Richie & 0.07 & 5.492 \\
\hline The Steve Miller Band & 0.38 & 12.166 \\
\hline Daryl Hall \& John Oates & 0.44 & 10.478 \\
\hline Blondie & 0.61 & 13.495 \\
\hline Olivia Newton-John & 0.17 & 3.112 \\
\hline Michael Jackson & 0.50 & 49.218 \\
\hline Robert John & 0.14 & 1.745 \\
\hline The Knack & 0.27 & 41.390 \\
\hline Andy Gibb & 0.26 & 1.422 \\
\hline Player & 0.80 & 11.581 \\
\hline Debby Boone & 0.17 & 2.310 \\
\hline Bill Conti & 0.59 & 11.599 \\
\hline The Miracles & 0.29 & 2.010 \\
\hline Bay City Rollers & 0.24 & 1.631 \\
\hline John Denver & 0.03 & 1.168 \\
\hline Labelle & 0.80 & 10.961 \\
\hline Barry White & 0.20 & 19.997 \\
\hline Grand Funk & 1.00 & 1.918 \\
\hline Charlie Rich & 0.15 & 6.771 \\
\hline Carpenters & 0.25 & 15.001 \\
\hline Michael Jackson & 0.40 & 13.490 \\
\hline Neil Young & 0.36 & 58.684 \\
\hline Cher & 0.47 & 6.448 \\
\hline Dawn & 0.06 & 4.736 \\
\hline The Beatles & 0.26 & 16.313 \\
\hline Ray Stevens & 0.21 & 0.355 \\
\hline The 5th Dimension & 0.24 & 1.823 \\
\hline The Beatles w/ Billy Preston & 0.37 & 26.074 \\
\hline Diana Ross \& The Supremes & 0.21 & 3.290 \\
\hline Jeannie C. Riley & 0.36 & 2.699 \\
\hline The Beatles & 0.72 & 26.566 \\
\hline The Supremes & 0.22 & 2.960 \\
\hline Percy Sledge & 0.80 & 34.599 \\
\hline The Mamas \& The Papas & 0.31 & 15.992 \\
\hline The Beatles & 0.52 & 36.127 \\
\hline The Beatles & 0.27 & 21.438 \\
\hline The Shangri-Las & 0.50 & 7.741 \\
\hline The Beatles & 0.38 & 42.738 \\
\hline The Essex & 0.10 & 0.010 \\
\hline Steve Lawrence & 0.15 & 0.205 \\
\hline The Shirelles & 0.17 & 0.593 \\
\hline Connie Francis & 0.11 & 0.251 \\
\hline The Tokens & 0.71 & 26.213 \\
\hline The Marcels & 0.42 & 6.401 \\
\hline Elvis Presley w/ the Jordanaires & 0.36 & 11.192 \\
\hline Brenda Lee & 0.21 & 3.242 \\
\hline Santo \& Johnny & 0.22 & 4.605 \\
\hline The Chipmunks w/ David Seville & 0.35 & 11.012 \\
\hline
\end{tabular}




$\begin{array}{ll}1958 & \text { It's Only Make Believe } \\ 1958 & \text { It's All in the Game } \\ 1957 & \text { All Shook Up } \\ 1957 & \text { Round and Round } \\ 1956 & \text { I Want You, I Need You... } \\ 1956 & \text { The Wayward Wind } \\ 1955 & \text { The Yellow Rose of Texas } \\ 1955 & \text { Cherry Pink (and Apple...) } \\ 1954 & \text { I Need You Now } \\ 1954 & \text { Oh! My Pa-Pa } \\ 1953 & \text { I'm Walking Behind You } \\ 1953 & \text { Till I Waltz Again } \\ 1952 & \text { Why Don't You Believe Me? } \\ 1952 & \text { Wheel of Fortune } \\ 1951 & \text { Cold, Cold Heart } \\ 1951 & \text { How High The Moon } \\ 1950 & \text { The Thing } \\ 1950 & \text { Rag Mop } \\ 1949 & \text { That Lucky Old Sun } \\ 1949 & \text { A Little Bird Told Me } \\ 1948 & \text { Buttons and Bows } \\ 1948 & \text { Twelfth Street Rag } \\ 1947 & \text { Ballerina } \\ 1947 & \text { Near You } \\ 1946 & \text { The Gypsy } \\ 1946 & \text { I Can't Begin To Tell You } \\ 1945 & \text { My Dreams Are Getting Better... } \\ 1945 & \text { Don't Fence Me In } \\ 1944 & \text { I'm Making Believe } \\ 1944 & \text { Besame Mucho (Kiss Me Much) } \\ 1943 & \text { I've Heard That Song Before } \\ 1943 & \text { I Had The Craziest Dream } \\ 1942 & \text { Jingle, Jangle, Jingle } \\ 1942 & \text { A String Of Pearls } \\ 1941 & \text { Chattanooga Choo Choo } \\ 1941 & \text { Daddy } \\ 1940 & \text { Frenesi } \\ 1940 & \text { I'll Never Smile Again } \\ & \end{array}$

$\begin{array}{lcc}\text { Conway Twitty } & 0.13 & 1.500 \\ \text { Tommy Edwards } & 0.22 & 0.946 \\ \text { Elvis Presley } & 0.44 & 18.986 \\ \text { Perry Como } & 0.20 & 0.319 \\ \text { Elvis Presley } & 0.23 & 3.416 \\ \text { Gogi Grant } & 0.11 & 0.024 \\ \text { Mitch Miller } & 0.23 & 0.439 \\ \text { Perez Prado w/ his orchestra } & 0.13 & 0.175 \\ \text { Eddie Fisher } & 0.13 & 0.061 \\ \text { Eddie Fisher } & 0.26 & 0.167 \\ \text { Eddie Fisher } & 0.26 & 0.061 \\ \text { Teresa Brewer } & 0.03 & 0.065 \\ \text { Boni James } & 0.26 & 0.041 \\ \text { Kay Starr } & 0.30 & 0.418 \\ \text { Tony Bennett } & 0.13 & 0.168 \\ \text { Les Paul \& Mary Ford } & 0.17 & 0.608 \\ \text { Phil Harris } & 0.39 & 0.088 \\ \text { Ames Brothers } & 0.05 & 0.006 \\ \text { Frankie Laine } & 0.25 & 0.165 \\ \text { Evelyn Knight } & 0.08 & \mathrm{~N} / \mathrm{A} \\ \text { Dinah Shore } & 0.26 & 0.388 \\ \text { Pee Wee Hunt w/ his orchestra } & 0.23 & \mathrm{~N} / \mathrm{A} \\ \text { Vaughn Monroe w/ his orchestra } & 0.24 & 0.009 \\ \text { Francis Craig w/ his orchestra } & 0.20 & 0.052 \\ \text { The Ink Spots } & 0.11 & 0.354 \\ \text { Bing Crosby \& Carmen Cavallaro } & 0.18 & 0.044 \\ \text { Les Brown w/ his orchestra } & 0.27 & 0.185 \\ \text { Bing Crosby \& The Andrews Sister: } & 0.26 & 0.793 \\ \text { The Ink Spots \& Ella Fitzgerald } & 0.09 & 1.065 \\ \text { Jimmy Dorsey w/ his orchestra } & 0.32 & 0.049 \\ \text { Harry James w/ his orchestra } & 0.00 & 0.744 \\ \text { Harry James w/ his orchestra } & 0.08 & 0.108 \\ \text { Kay Kryser w/ his orchestra } & 0.04 & 1.454 \\ \text { Glenn Miller w/ his orchestra } & 0.14 & 2.223 \\ \text { Glenn Miller w/ his orchestra } & 0.08 & 1.314 \\ \text { Sammy Kaye w/ his orchestra } & 0.13 & 0.035 \\ \text { Artie Shaw w/ his orchestra } & 0.16 & 0.917 \\ \text { Tommy Dorsey w/ his orchestra } & 0.15 & 4.120\end{array}$

